\title{
Integrated water resources management approach in mitigating the potential impacts of climate change on hydrology in Gurara reservoir catchment, Northwest Nigeria
}

\author{
Ifie-emi Francis Oseke ${ }^{1}$, Geophery Kwame Anornu ${ }^{2}$, Kwaku Amaning Adjei ${ }^{2}$, and \\ Martin Obada Eduvie ${ }^{1}$ \\ ${ }^{1}$ Department of Training, National Water Resources Institute, Mando-Road, Kaduna, Nigeria \\ ${ }^{2}$ Department of Civil Engineering, Kwame Nkrumah University of Science and Technology, Kumasi, Ghana
}

Correspondence: Ifie-emi Francis Oseke (engroseke@gmail.com)

Published: 16 November 2021

\begin{abstract}
The strategies and actions in the management of African River Basins in a warming climate environment have been studied. Using the Gurara Reservoir Catchment in North-West Nigeria as a case study, summations were proposed using hypothetical climate scenarios considering the Global Climate Models prediction and linear trend of the data. Four (4) proposed scenarios of temperature increase (1\% and $2 \%)$ coupled with a decrease in precipitation of $(-5 \%$ and $-10 \%)$ were combined and applied for the study area. The Water Evaluation and Planning Tool was used to model and evaluates the impact of the earth's rising temperature and declining rainfall on the hydrology and availability of water by investigating its resilience to climate change. Modelling results indicate a reduction in available water within the study area from $4.3 \%$ to $3.5 \%$ compared to the baseline with no climate change scenario, revealing the current water management strategy as not sustainable, uncoordinated, and resulting in overexploitation. The findings could assist in managing future water resources in the catchment by accentuating the need to put in place appropriate adaptation measures to foster resilience to climate change. Practically, it is pertinent to shape more effective policies and regulations within catchments for effective water resources management in reducing water shortage as well as achieving downstream water needs and power benefit in thefuture, while also allowing flexibility in the operation of a reservoir with the ultimate goal of adapting to climate change.
\end{abstract}

\section{Introduction}

The hydrology of large rivers in the world has been experiencing changes in their hydrological characteristics and variations in their morphological processes (Awotwi et al., 2015). Although these observable changes and variations, have widely been attributed to the impact of climate change (Wang and Hejazi, 2011). Climate change in itself can be best described as the average change in the weather. Although the climate is intertwined and closely related to weather, there are important differences (Lehmann et al., 2017; Salvati et al., 2017). A common distinction is a difficulty encounter by scientists in predicting the weather a few weeks while con- fidently predicting the climate in 50 years (Lehmann et al., 2017; Awotwi et al., 2015). According to Intergovernmental Panel on Climate Change (IPCC, 2017; Salvati et al., 2017), the past two centuries have seen a continuous increase in the surface temperature of the earth resulting in the occurrence of extreme weather and variability in precipitation leading to a reduction in runoff (Lehmann et al., 2017). On the other hand, anthropogenic activities construction of reservoirs, irrigation canals, alternate land use causing an increase in industrial water consumption have also resulted in changes in hydrological characteristics especially runoff (Kundzewicz, 2004; Lehmann et al., 2017). 
Table 1. Land use and land cover around GRC (Source: modified from WEAP model outcome).

\begin{tabular}{llrr}
\hline & \multicolumn{3}{c}{ Land Use in upper Gurara catchment } \\
\cline { 2 - 4 } S/N & Category & Area $\left(\mathrm{km}^{2}\right)$ & Percentage \\
\hline 1 & Agricultural land and wet land & 339.7 & $15.8 \%$ \\
2 & Forest land and wood land & 722.4 & $33.6 \%$ \\
3 & Wet land & 666.5 & $31.0 \%$ \\
4 & Urban land & 303.2 & $14.1 \%$ \\
5 & Water body and grass land & 116.1 & $5.40 \%$ \\
6 & Urban land & 2.150 & $0.10 \%$ \\
\hline & Total & 2,150 & $100 \%$ \\
\hline
\end{tabular}

According to Abdullahi et al. (2016), in water basins, the impact of climate change is felt in the alteration of the amount and timing of runoff, thereby increasing the challenges in the coping capacities of large river basins especially in the wake of increasing water demands thus bringing higher risks of water shortages and food security. Meanwhile, the impact of climate change can go well beyond the water sector since many of the most serious effects of climate change on non-water areas are mediated via water (Salvati et al., 2017; Lehmann et al., 2017). These concerns have been the challenges among water resources managers in making efforts to protect the ecosystem especially the Gurara Reservoir Catchment (GRC) by quantifying the cumulative impact from the changing trend of climate and other anthropogenic activities on runoff using a long-term hydrological data-driven approach.

The GRC is Nigeria's pioneer and only reservoir catchment performing a water transfer operation $(3 \mathrm{~m}$ wide and $75 \mathrm{~km}$ long pipeline). In the catchment, water is transferred from the Gurara Reservoir to Lower Usuma Reservoir in the Federal Capital Territory Abuja, the administrative capital of Nigeria, serving over 2.7 million people. The need to transfer water was initiated when from the fact that in 1999, Abuja had a population of 2.1 million and this number has been projected to increase to about 7 million in the next 50 years. This rapid population growth and accompanying developments brought about the tremendous surge in demand for water which was essential for sustaining its inhabitants. Before this study, there is limited converge on assessing the impact of climate change on hydrology using integrated water resources management approach within the (GRC) to the best knowledge of the authors, as such there is the need to fill this identified gap using multiple climate change scenarios while considering plausible socio-economic developments. This is because freshwater resources at GRC are considered very important by stakeholders in the basin. In this regard, the aim of this paper is to analyze the impact of climate change on hydrology within the GRC for estimating water availability and use. In particular, the focus is on estimating the runoff into the Gurara reservoir managed by the De- partment of Dams and Reservoir, Federal Ministry of Water Resources, Abuja Nigeria. Besides the water transfer operation, the multipurpose reservoir also supplies water to the Azare-Jere irrigation farms as well as generating $30 \mathrm{MW}$ of hydroelectric power. Thus, there is a high priority placed on the reservoir due to its strategic importance

\section{Material and methods}

\subsection{Study area}

The GRC is a transboundary catchment located in West Africa (Nigeria). The catchment is shared by Kaduna State in the West, Niger State in the North, Plateau State in the East and Abuja in the South. Remotely, the catchment cuts across Kachia and Kagarko Local Government Areas in Kaduna State and Bwari Area Council of Nigeria's FCT, covering an area of approximately $150 \mathrm{~km}^{2}$. The catchment falls within Latitude 090:32 N to 090:48' $\mathrm{N}$ and Longitude 070:29 $\mathrm{E}$ and 070:49' E.

\subsection{Data}

The major data types are hydrological time series data, water demand data. However, due to the lack of sufficient hydrological data, the Soil Conservation Service Runoff Curve Number (SCSRCN) method was used for computing the runoff. The Curve Number $(\mathrm{CN})$ utilized in this study as input for the SCSRCN method to compute the runoff was adopted from a previous study by Coyne et Bellier and de Crown (2008). The characteristics of Land cover within the GRC are listed in Table 1.

\subsection{Model setup and simulation based on the WEAP platform}

A WEAP model was set-up for the catchment consisting of meteorological and other relevant input data used for the hydrological modeling based on the WEAP platform. The model builds and analyzes different future scenarios using hypothetical climate assumptions about the impacts of cli- 


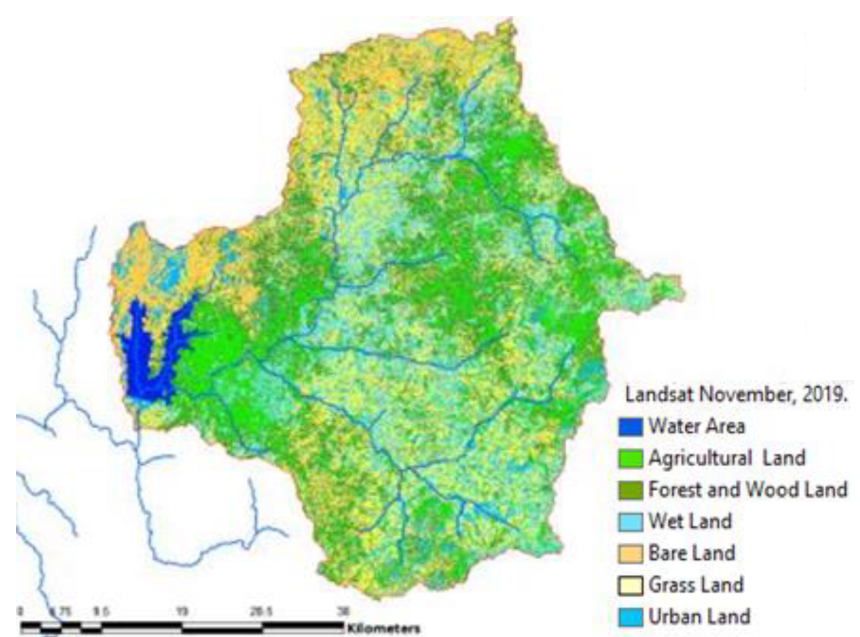

Figure 1. Land cover map showing changes within the GRC from 2010, the period after dam construction.

Table 2. Hypothetical climate change scenarios.

\begin{tabular}{lll}
\hline Scenario & $\begin{array}{l}\text { Change in } \\
\text { Temperature }\end{array}$ & $\begin{array}{l}\text { Change in } \\
\text { Precipitation }\end{array}$ \\
\hline Baseline & No Change & No Change \\
Scenario 1 & Temp $(+0.01)$ & Precip $(-0.05)$ \\
Scenario 2 & Temp $(+0.02)$ & Precip $(-0.10)$ \\
\hline
\end{tabular}

mate change on hydrology for water availability. This is to ensure that informed policies are made on the available water and water use dynamics.

\subsection{Performance and evaluation of calibrated and validated model}

The reliability of the simulation was assessed by two indices; the Nash-Sutcliff Efficiency (NSE) and the Coefficient of Determination $\left(R^{2}\right)$ for performance, as proposed by Moriasi et al. (2007). The missing dataset was filled using the inverse distance weighting method based on Awotwi et al. (2015).

\subsection{Climate change scenarios}

This study relied on purely hypothetical scenarios derived from the outputs of General Circulation Models to assess the potential impacts of climatic change on runoff in GRC. The hypothetical scenario approach is well documented according to Abdullahi et al. (2014). The choice of using hypothetical temperature increases of 1 and $2{ }^{\circ} \mathrm{C}$ reflects the consensus that greenhouse emission will produce rises in this range, given an equivalent doubling of atmospheric $\mathrm{CO}_{2}(\mathrm{Gebre}$ and Ludwig, 2015). The climate scenarios are listed in Table 2.

Subsequently, a reduction of precipitation of $5 \%$ and $10 \%$ was used owing to greater uncertainty surrounding estimates of changes in regional precipitation. Both the increases and

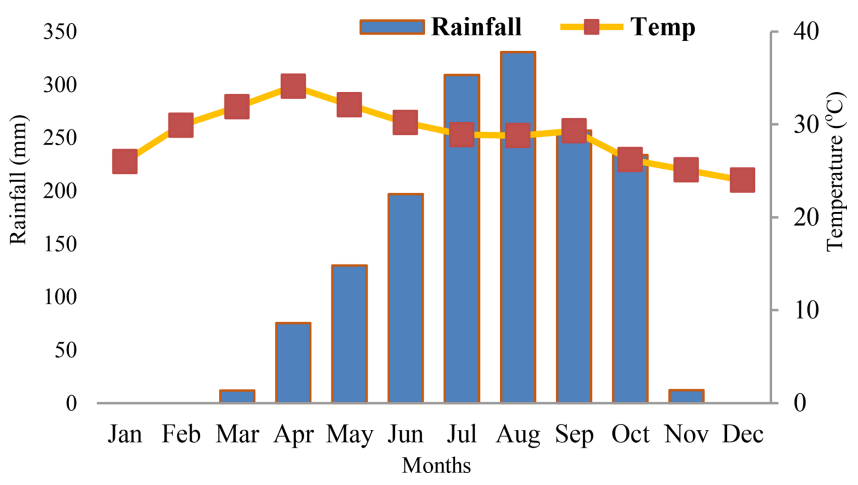

Figure 2. Mean monthly rainfall and temperature relationship for baseline scenario from 1988 to 2019 in GRC.

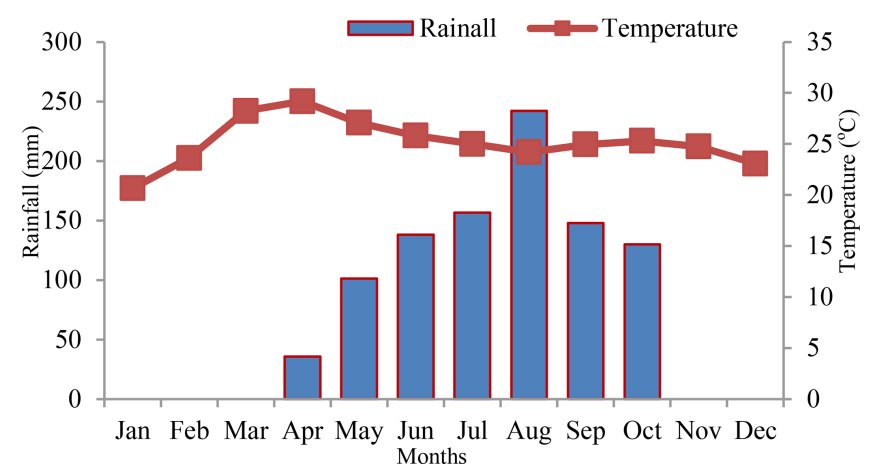

Figure 3. Mean monthly rainfall and temperature relationship for scenario 1 from 1988 to 2019 in GRC.

decreases in average temperature and precipitation respectively are modelled in this study.

\subsection{Runoff computation at Gurara reservoir catchment}

The general form of SCS-CN equation for computing the runoff is given as follows

$Q=\frac{\left(P-l_{\mathrm{a}}\right)^{2}}{\left(P-l_{\mathrm{a}}\right)+S}$

where $Q=$ runoff, $P=$ rainfall, $S=$ potential maximum retention after runoff begins and $l_{\mathrm{a}}=$ Initial abstraction and is highly variable but generally is correlated with soil. $l_{\mathrm{a}}$ is estimated using:

$l_{\mathrm{a}}=0.2 S$

$\mathrm{S}$ is related to the soil and covers conditions of the catchment through the runoff $\mathrm{CN}$ by the Eq. (2) and is estimated using:

$S=\frac{1000}{\mathrm{CN}}-10$

A composite runoff $\mathrm{CN}$ value of $75 \%$ developed by Coyne et Bellier and de Crown (2008) from previous was adopted. According to Coyne et Bellier and de Crown (2008). The 
Table 3. Different climate warming impact on scenarios to water availability based on simulation of the sources for Gurara River.

\begin{tabular}{lrrr}
\hline & \multicolumn{3}{c}{ Amount of water available (mcm) } \\
\cline { 2 - 4 } & $\begin{array}{r}\text { Baseline } \\
\text { No Change }\end{array}$ & $\begin{array}{r}\text { Scenario one } \\
+1.0{ }^{\circ} \mathrm{C},-10 \% \mathrm{P}\end{array}$ & $\begin{array}{r}\text { Scenario two } \\
+2.0^{\circ} \mathrm{C},-10 \% \mathrm{P}\end{array}$ \\
\hline Available water $(\mathrm{mcm})$ & 4777 & 4458 & 4379 \\
Difference $(\mathrm{mcm})$ & $\mathrm{n} / \mathrm{a}$ & 319 & 398 \\
$(\%)$ of reduction & $\mathrm{n} / \mathrm{a}$ & 3.5 & 4.3 \\
\hline
\end{tabular}

n/a: not applicable.

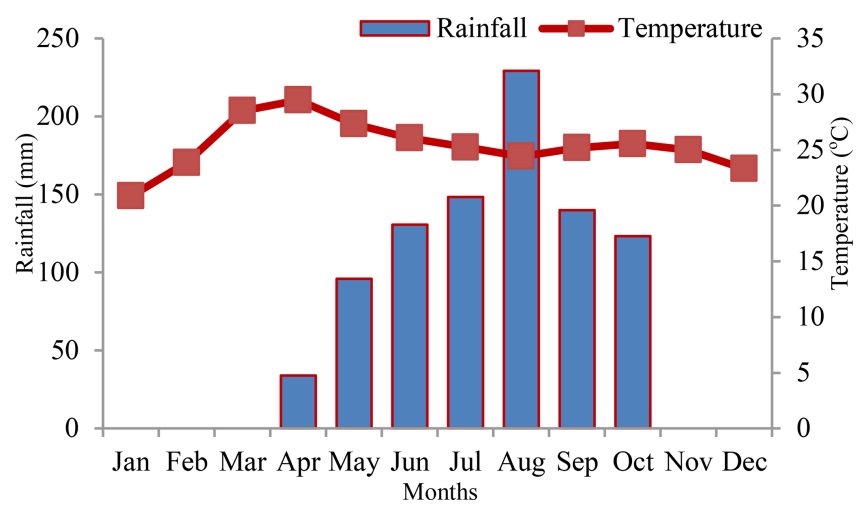

Figure 4. Mean monthly rainfall and temperature relationship for scenario 2 from 1988 to 2019 in GRC.

value is because of the development level within the catchment and bearing in mind that the catchment is also highly forested (Coyne et Bellier and de Crown, 2008). Shown in Fig. 1 is the land cover map obtained from the hybrid classification of the 2019 Enhanced Thematic Mapper (ETM+) Landsat image within the GRC. Thus Eqs. (1), (2), and (3) becomes:

$$
Q=\frac{(P-0.6667)^{2}}{(P+2.6666)}
$$

\subsection{Analysis of climate change impact on hydrology}

The analysis to quantify the available water in all scenarios from the hypothetical increase in the indicators of climatic change within the catchment was evaluated based on Eq. (5).

$\%$ Impact $=\frac{\text { available Water Under a Scenario }}{\text { Available Water from observation }} \times 100$

\section{Results}

\subsection{Temperature and rainfall}

The mean monthly temperature and precipitation data obtained from the Nigerian Meteorological Agency (FMWR, 2013), is illustrated in Fig. 2 (baseline scenario), while the

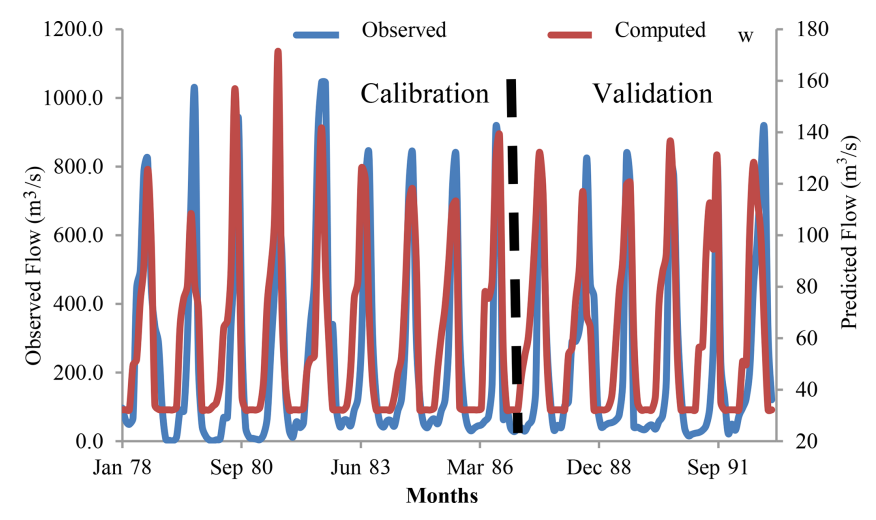

Figure 5. Computed runoff fit on the observed runoff for the period 1978 to 1991 .

hypothetical climate change Scenarios is shown in Fig. 3 (Scenario 1) and Fig. 4 (Scenario 2). The hottest period occurring in the months of March and April, with temperature values between 30.6 to $36.5^{\circ} \mathrm{C}$. December is the coldest month with an average temperature ranging from 23.5 to $24.0^{\circ} \mathrm{C}$. The mean monthly precipitation reveals a varying trend between $350 \mathrm{~mm}$ in the dry season to $1412 \mathrm{~mm}$ in the wet season, with about $80 \%$ occurring between July and September. The heaviest rainfall occurs in the month of August with a value of $294.8 \mathrm{~mm}$.

\subsection{Runoff}

Illustrated in Fig. 5 is the comparison of observed and computed hydrographs for calibration and validation of the runoff in a monthly time step (1978 through 1991). A near excellent correlation was achieved and the computed percentage change in runoff followed the net supply and fits reasonably well with the observed. This fit statistically justifies the acceptability of our computed for hydrological modelling within the GRC. The calibration and validation using the SCSRCN method for the observed and computed runoff resulted in NSE: calibration 0.72 : validation 0.69 and $R^{2}$ : calibration 0.72 : validation 0.69 . 


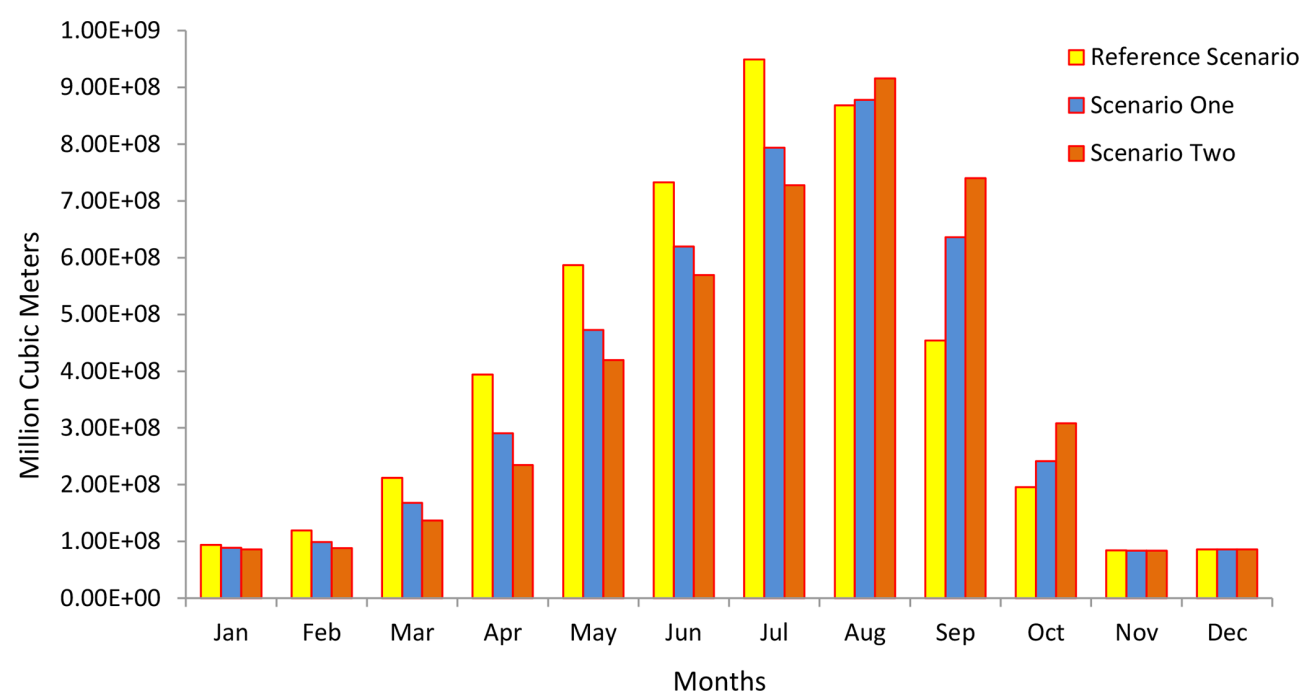

Figure 6. Simulated inflow $(\mathrm{mcm})$ under current and future climate change for all scenarios.

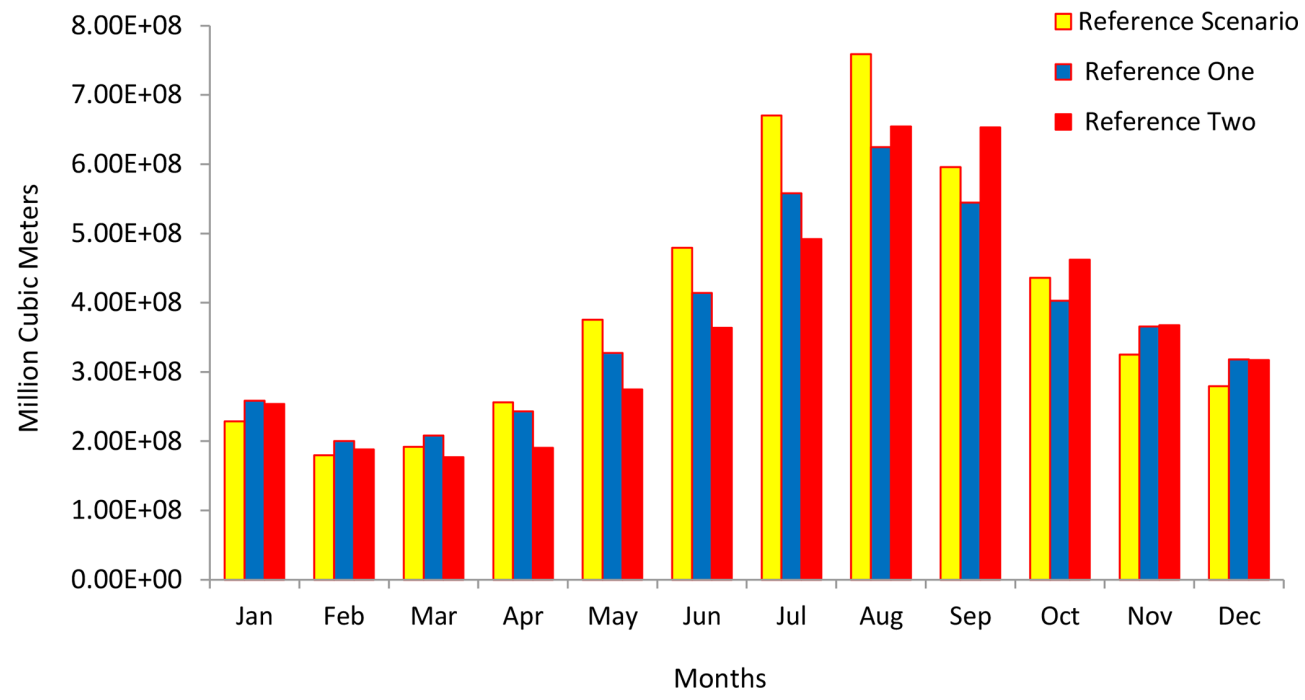

Figure 7. Simulated outflow $(\mathrm{mcm})$ under current and future climate change for all scenarios.

\subsection{Water availability}

The result from the analysis of climate change impact is listed in Table 3. The cumulative inflow to the catchment is illustrated in Fig. 6, while the outflow is shown in Fig. 7 and the water balance for inflow, outflow, consumption, and evaporation is shown in Fig. 8, respectively.

The result reveals the different amounts of water available based on the simulated model due to the different hypothetical climate scenarios.

\section{Discussion}

The impact of climate change on hydrology is not uniform hence the water availability is season-dependent for all sce- narios. The projected mean annual runoff for the simulation period in the WEAP model shows a reduction in available water compared to the baseline values. These results indicate that under scenario 2 regarded as an increase in temperature by $2^{\circ}$ and a decrease in precipitation by $10 \%$, the available water within the catchment is estimated at $4379 \mathrm{mcm}$, a reduction from $4458 \mathrm{mcm}$ in scenario 1 . These translate into significant decreases in mean annual runoff relative to the baseline value, the mean annual runoff values for scenario 1 and scenario 2 showed a decrease of $3.5 \%$ and $4.3 \%$ respectively compared to the baseline (Table 3 ). Accordingly, the statistics of the available water within the catchment under the baseline and the hypothetical scenarios (see Table 3) show sensitivity to variability under climate change, compared to baseline. Abdullahi et al. (2014) reported a similar 


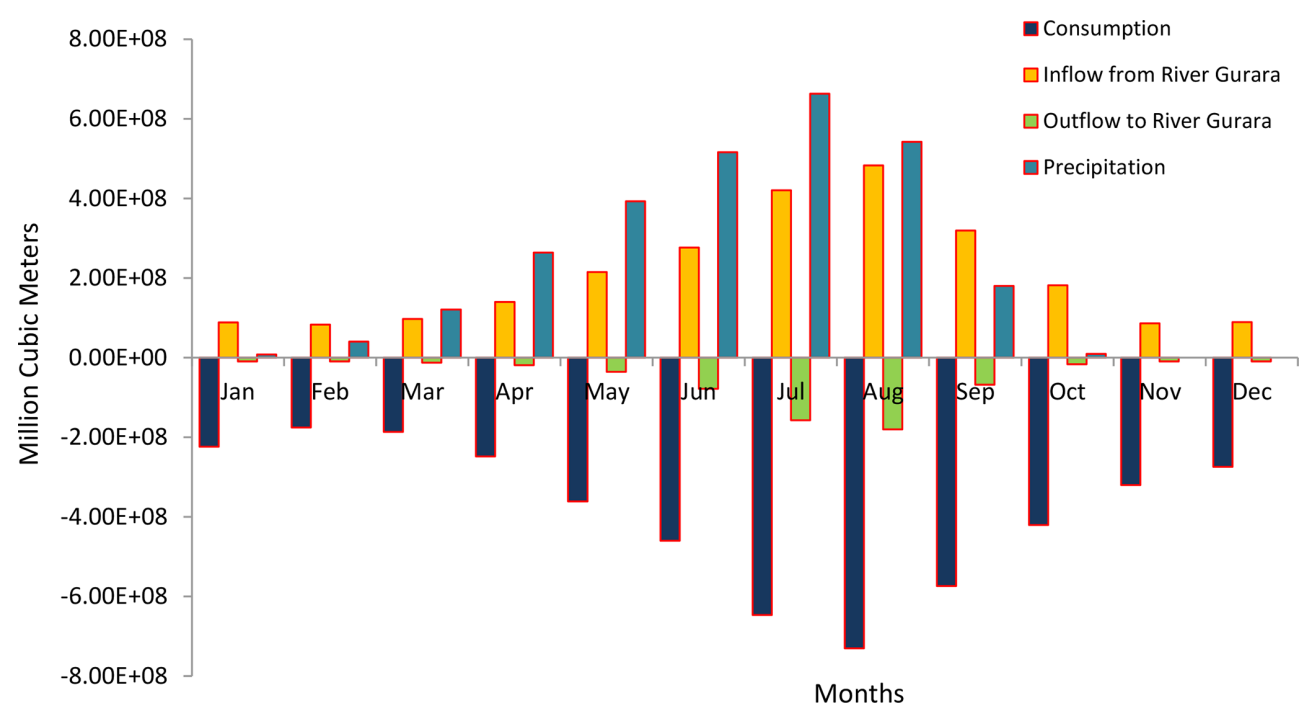

Figure 8. Water balance showing consumption, inflow, outflow and evaporation all scenarios with respect to baseline scenarios.

observation for the entire Sokoto Rima River Basin. The reduction in the percentage of available water under the different scenarios is more significant for the annual runoff, as it is the basis for the catchment's relevancy. The WEAP simulated model adopted for this study offers a simplified representation of the complex workings of the catchment's hydrology in estimating water availability by representing the actual conditions within the catchment while using various scenarios and key assumptions.

\section{Conclusions and recommendations}

The analysed projected temperature and rainfall hypothetical-based climate change scenarios show an increase in temperature and decrease in rainfall in the future within the catchment. The sensitivity analysis identifies runoff as the most sensitive input parameter and was much attention in the model calibration process. The runoff data were computed using the SCSRCN method while the impact analysis was modelled in WEAP. The WEAP model was successfully set up, calibrated, and validated and the climate change impact analysis was performed. The statistical correlation at calibration and validation carried out revealed monthly runoff was well predicted, and adequate for hydrological modelling during the calibration and validation periods.

Practically in Nigeria like many developing nations, a need to prepare adequately for the negative impact of climate change cannot be over emphasised, the development of models predicting projected climate change scenarios is recommended to serves as a platform that enables stakeholders better understand our climate system. In addition offering a means to access, plan and implement sustainable programs that will assist in combating these changes, thereby making our nation less vulnerable. Besides, as more climatic data are available, further research needs to be carried out to model variations based on decades, yearly, monthly and daily changes as a strategy for implementing integrated water resources management considering uncertainties and increasing warming climate for sustainability.

Data availability. The underlying research data can be accessed from the Federal Ministry of Water Resources Abuja Nigeria on request.

Author contributions. All the authors IFO, GKA, KAA, and MOE were involved in the concept development, data collection, data analysis and manuscript write-up.

Competing interests. The contact author has declared that neither they nor their co-authors have any competing interests.

Disclaimer. Publisher's note: Copernicus Publications remains neutral with regard to jurisdictional claims in published maps and institutional affiliations.

Special issue statement. This article is part of the special issue "Hydrology of Large River Basins of Africa". It is a result of the 4th International Conference on the "Hydrology of the Great Rivers of Africa", Cotonou, Benin, 13-20 November 2021. 


\section{References}

Abdullahi, S. A., Muhammad, M. M., Adeogun, B. K., and Mohammed, I. U.: Assessment of Water Availability in the Sokoto Rima River Basin, Res. Environ., 4, 220-233, 2014.

Awotwi, A., Yeboah, F., and Kumi, M.: Assessing the impact of land cover changes on water balance components of White Volta Basin in West Africa, Water Environ. J., 29, 259-267, 2015.

Coyne et Bellier and De Crown Lot, A. (Eds.): Dam and Associated Works - Design and Works Progress April 2001-March 2007, Gurara Water Transfer Project to Federal Capital Territory, The Regent Printing and Publishing Ltd, Abuja, 2008.

Federal Ministry of Water Resources FMWR (Eds.): Gurara water transfer project to federal capital territory LOT A: Dam and associated works, Design and works progress April 2001-March 2007, Abuja, FMWR, 2008.

Gebre, S. L. and Ludwig, F: Hydrological Response to Climate Change of the Upper Blue Nile River Basin: Based on IPCC 5th Assmnt Rept, J. Climatol. Weather Forecast., 3, p. 121, 2015.

Kundzewicz, Z. W.: Searching for change in hydrologic data, Hydrol. Sci. J., 49, 3-6, 2004.
Lehmann, D., Brinkmann, K., Diogo, R. V., and Buerkert, A.: Temporal and spatial changes of land use in rare metal mining areas of Rwanda, Int. J. Mining. Reclam. Environ., 31, 519-529, 2017.

Moriasi, D. N., Arnold, J. G., Van Liew, M. W., Bingner, R. L., Harmel, R. D., and Veith, T. L.: Model evaluation guidelines for systematic quantification of accuracy in watershed simulations, Trans. Am. Soc. Agr. Bio. Engrs., 50, 885-900, 2007.

Salvati, L., De Zuliani, E., Sabbi, A., Cancellieri, L., Tufano, M., Caneva, G., and Savo, V.: Land-cover changes and sustainable development in a rural cultural landscape of central Italy: classical trends and counter-intuitive results, Int. J. Sustain Dev. Wld. Ecol., 24, 27-36, 2017.

Wang, D. and Hejazi, M.: Quantifying the relative contribution of the climate and direct human impacts on mean annual streamflow in the contiguous United States, Water Resour. Res., 47, 1-16, 2011. 